\title{
AS TECNOLOGIAS DIGITAIS PARA EDUCAÇÃO \\ DA PESSOA COM TRANSTORNO DO ESPECTRO \\ AUTISTA (TEA)
}

\section{DIGITAL TECHNOLOGIES FOR EDUCATION OF PERSONS WITH AUTISTIC SPECTRUM DISOR- DERS (ASD)}

Danielle Santos Machado ${ }^{1}$

Resumo: O processo de inclusão se faz primordial nos dias atuais. Muito ouvimos discorrer sobre isso. Dessa forma, esse trabalho se constitui de pesquisa bibliográfica a respeito do processo de uso de tecnologias digitais para a educação da pessoa com Transtorno do Espectro Autista (TEA). Nosso objetivo é compreender como as tecnologias digitais podem auxiliar no ensino da criança com TEA. Para isso, procuramos artigos científicos em bases de dados que discorressem a respei- to do assunto em questão. Abordamos aspectos da criança com TEA, inclusão na escola, bem como a questão da tecnologia para inclusão desses alunos no ambiente escolar.

Palavras-chaves: Tecnologia.

Autismo. Inclusão.

Abstract: The process of inclusion is paramount today. We hear a lot about this. Thus, the data research program for the teaching of digital technologies

1 Graduada em Pedagogia, Especialista em Educação especial, Psicopedagogia clínica e institucional, Gestora do Instituto Kognitiv.

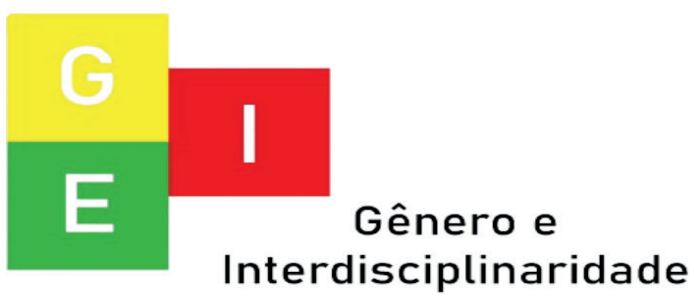


ISSN: 2675-7451

Vol. 02 - n 06 - ano 2021

Editora Acadêmica Periodicojs

for the education of the person with Autism Spectrum Disorder (ASD). The TEA. For this, the scientific data are searched in databases that discuss the subject in question. We address aspects of the child with ASD, including at school, as well as the issue of technology for the student in the school environment.

Keywords: Technology. Autism. Inclusion.

\section{INTRODUÇÃO}

Incluir todas as pessoas, mesmo que tenham deficiência, é fundamental para a inclusão de todos. Esse passo deve ser iniciado em casa pela família, posteriormente na escola e na sociedade, as pessoas devem se adaptar a viver com as diferenças.

Diante das mudanças vividas no decorrer do processo escolar, cada vez mais tem sido reiterada a importância da preparação de profissionais e educadores, em especial do professor de classe comum, para o atendimento das necessidades educativas de todas as crianças, com ou sem deficiências.

$\mathrm{Na}$ medida em que a orientação inclusiva implica um ensino adaptado às diferenças e às necessidades individuais, os educadores precisam estar habilitados para atuar de forma competente junto aos alunos inseridos, nos vários níveis de ensino.

O ambiente escolar tem passado por transformações no que diz respeito ao método de ensino, onde os professores têm se qualificado visando a qualidade de ensino e abrangência da demanda de alunos.

Quando o ambiente escolar é inclusivo e não pode excluir nenhum aluno, pois traz

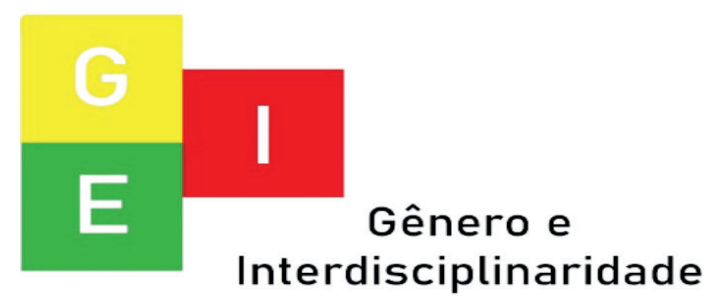


ISSN: $2675-7451$

Vol. 02 - n 06 - ano 2021

Editora Acadêmica Periodicojs

vantagens as crianças, além de de ações e programas voltados

abordar a questão de diversidade

à temática. Docentes, diretores

e igualdade, facilitando o proces-

e funcionários apresentam pa-

so de aprendizagem.

O processo de inclusão em escolas é algo bastante desafiador, tendo em vista a preparação que os profissionais precisam ter para receber esses alunos com deficiência, além da estrutura da escola que precisa estar adaptada para o recebimento de alunos com diversas deficiências. É necessário que os pais e profissionais estejam preparados para enfrentar as possíveis dificuldades existentes. Além disso, o professor precisa ter um olhar aguçado, que vai além do conhecimento teórico, para perceber e identificar as necessidades individuais dos alunos.

$\mathrm{Na}$ inclusão educacional, faz-se necessário o envolvimento de todos os membros da equipe escolar no planejamento

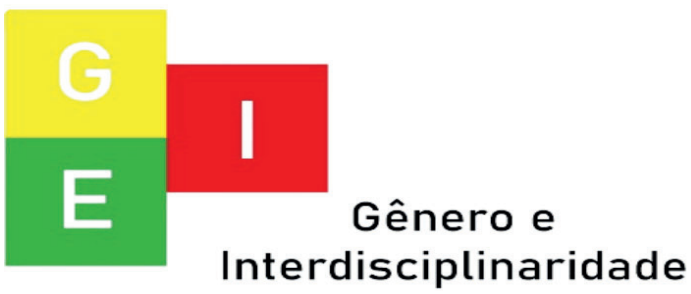
cação inclusiva se mostra com limites e dificuldades, em virtude da falta de formação dos professores das classes regulares, para atender a demanda da educação básica e das classes regulares.

Vivemos uma época em que muito se fala de inclusão escolar com alunos com necessidades especiais na rede escolar, sendo assim esse artigo se trata de um tema extremamente atual, 
ISSN: 2675-7451

Vol. 02 - n 06 - ano 2021

Editora Acadêmica Periodicojs

pois a cada dia a questão da diversidade tem aflorado em nosso cotidiano. A criança com TEA precisa ser alfabetizada, pois isso é fundamental para seu cotidiano social, tendo em vista as possibilidades de condições que facilitem o processo de aprendizagem e desenvolvimento dos alunos com necessidades especiais.

As limitações que levam a adoção de políticas de educação inclusiva são basicamente de duas naturezas distintas, as limitações de aspecto físico como a cegueira, a surdez, paralisia ou ausência de membros locomotores e as limitações de aspecto cognitivo que são patologias ou síndromes que comprometem a capacidade de aprendizagem do indivíduo. Por meio da utilização de ferramentas e abordagens de ensino específicas é possível contornar essas limitações, incentivando uma democratização do ensino e integração social das crianças com algum tipo de deficiência (PORTAL EDUCAÇÃO, 2018).

A adoção de interpretes de libras, impressão de materiais em Braille e construção de rampas de acesso são soluções destinadas as pessoas com limitações físicas.

Para os autistas de limitações cognitivas é recomendada a estruturação minuciosa do plano de ensino e utilização de ferramentas de caráter mais lúdico que os meios tradicionais.

Diante do exposto, buscou-se responder a seguinte indagação: como as tecnologias digitais podem auxiliar no ensino da criança com Transtorno do Espectro Autista?

Para responder ao nosso objetivo, optamos pelo uso da pesquisa bibliográfica, por meio de artigos e trabalhos referentes

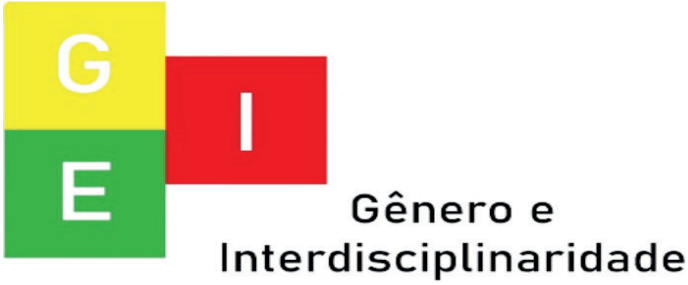


ISSN: 2675-7451

Vol. 02 - n 06 - ano 2021

Editora Acadêmica Periodicojs

ao tema.

O Transtorno do Espectro Autista será escrito pela sigla TEA. E sobre a disposição do trabalho, será organizado da seguinte forma:

O tópico 2 discorre a respeito do Transtorno do Espectro Autista, onde faremos uma breve abordagem sobre a síndrome; o subtópico 2.1 abordará a questão da inclusão escolar para os alunos que sofrem com o TEA; já o subtópico 2.2 abrange

as tecnologias da educação para as crianças com TEA e verificando como isso pode ser benéfico para elas, e, por fim, o tópico 3 que é a conclusão, onde faremos um apanhado geral do trabalho.

TRANSTORNO DO ESPECTRO AUTISTA (TEA)
O Transtorno do Espectro Autista (TEA) é uma síndrome definida por alterações presentes desde muito cedo, ou seja, pode ser apresentada desde antes dos três anos de idade, e se tornam visíveis ao longo do crescimento (SANTOS; GRILLO, 2015).

Desta forma, a criança apresenta o desenvolvimento comprometido, bem como socialização e imaginação afetados, fazendo com que a criança mostre dificuldade na fala, expressões e ideias. É um transtorno que se manifesta na infância e tem continuidade na vida adulta.

Schwartzman (apud RODRIGUES, 2012, p. 10) sintetiza o autismo como "[...] uma síndrome definida por alterações presentes desde idades muito precoces e que se caracteriza, sempre, pela presença de desvios

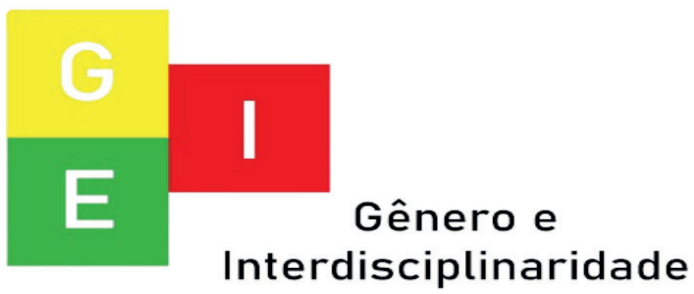


Vol. 02 - n 06 - ano 2021

Editora Acadêmica Periodicojs

nas relações interpessoais, linguagem, comunicação, jogos e comportamento".

$\mathrm{O}$ diagnostico do TEA se desenvolve com de forma clínica, por meios de profissionais da área da saúde (como médicos, psiquiatras e neuropsiquiatras), baseados em discursos da família, ou seja, relato dos pais e responsáveis que convivem com a criança, fazendo observações sobre seu comportamento. Além disso, os médicos se firmam em avaliações de outros especialistas da saúde, como psicólogos e psicopedagogos. Para um diagnóstico preciso também são feitos exames laboratoriais e de imagens (PEREIRA et al., 2015).

O TEA abrange diferentes síndromes marcadas por perturbações de desenvolvimento neurológicos com duas características principais que podem ser manifestadas de forma conjunta ou isolada. Essas características, segundo Alves (2016, p. 178-179), consistem em:

a) déficit persistente na comunicação social e na interação social em múltiplos contextos, atualmente ou por histórico prévio (déficit na reciprocidade sócio emocional [...], compartilhamentos reduzidos de interesses, emoções e afetos, dificuldade para iniciar ou responder as interações sociais, déficit no comportamento comunicativo não verbal usados para comunicação social, ausência de expressões faciais [...], déficit para desenvolver, manter e compreender relacionamentos);

b) padrões restritivos e repetitivos de comportamento, interesses ou atividades, conforme manifestado atualmente

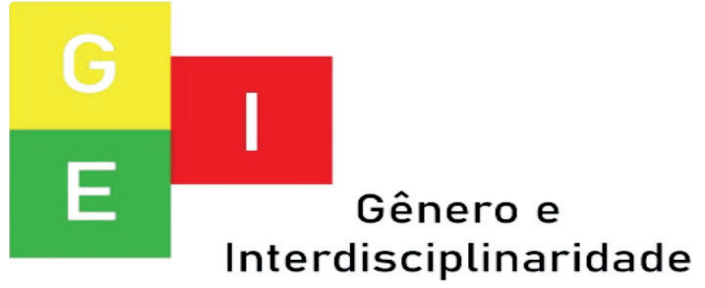


ISSN: 2675-7451

Vol. 02 - n 06 - ano 2021

Editora Acadêmica Periodicojs

ou por história prévia

(movimentos moto-

res, uso de objetos e

falas estereotipadas, insistência nas mesmas coisas, adesão flexível ou rotinas padrões, interesses fixos e altamente restritivos que são anormais em intensidade ou foco) (ALVES, 2016, p. 178-179).

Bruna (2018, não paginado) afirma que o TEA também é

[...] chamado de Desordens do Espectro Autista (DEA ou ASD em inglês), recebe o nome de espectro (spectrum), porque envolve situações e apresentações muito diferentes umas das outras, numa gradação que vai da mais leves à mais grave. Todas, porém, em menor ou maior grau estão relacionadas, com as dificuldades de comunicação e relacionamento social (BRUNA, 2018, não paginado).

A respeito do quadro clínico, Bruna (2018) afirma que podem ser classificados em 3 níveis:

é onde o grau de comprometimento pode variar muito. Nesse estágio, embora os autistas possam compreender enunciados simples, eles têm dificuldade de compreensão e aprendem só o sentido literal das palavras, ou seja, não entendem duplo sentido. Se tratam de crianças isoladas, que não aprendem a falar e nem olhar outras pessoas nos olhos, não retribuem sorrisos e repetem movimentos sem muito significado.

Autismo de alto desempenho (antigamente cha-

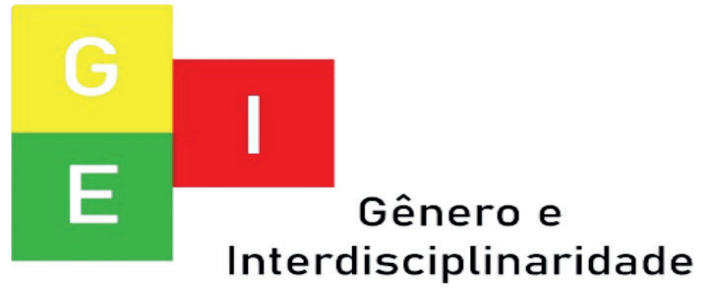


Vol. 02 - n 06 - ano 2021

Editora Acadêmica Periodicojs

mado de síndrome de Asperger): rer de múltiplas causas, entre os autistas são verbais e inteli- elas fatores genéticos, biológicos gentes, nessa classificação os aue ambientais. Não existe um tratistas têm a síndrome de forma tamento padrão para esse transreduzida. torno de desenvolvimento, pois - Distúrbio global é importante analisar cada pado desenvolvimento sem outra especificação (DGD-SOE): os ciente de forma individual, além autistas são considerados dentro de levar em conta o acompanhamento e participação dos pais e do espectro do autismo (dificulfamiliares, bem como da equipe dade de comunicação e de interação social), entretanto os sintomas não são suficientes para incluí-los em nenhuma das categorias específicas do transtorno, o que torna o diagnóstico bem mais difícil. de profissionais que atendem o paciente (PEREIRA et al., 2015). Crianças com autismo precisam de um tratamento diferenciado no ambiente escolar e é sobre essa questão que discorreremos nos tópicos posteriores.

O autismo é uma conInclusão escolar para os alunos dição permanente, ou seja, não com TEA abandona o individuo com o passar do tempo, não tendo cura, mas pode sofrer alterações com o passar dos tempos (SANTOS; GRILLO, 2015).

O autismo pode decor-

Sabemos que existem políticas que lutam pela inclusão de pessoas com necessidades especiais, entre essas leis, podemos citar a Constituição Federal

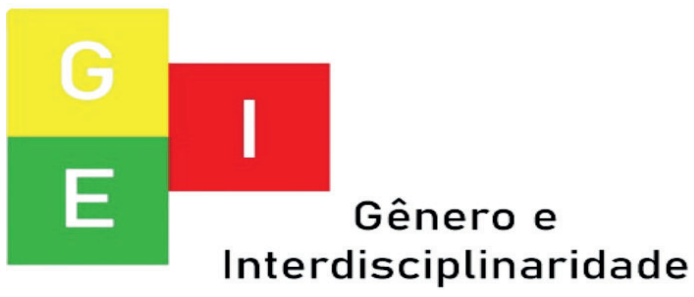


ISSN: 2675-7451

Vol. 02 - n 06 - ano 2021

Editora Acadêmica Periodicojs

(1988), a Lei de Diretrizes e Ba-

ses da Educação Nacional (1996)

e as Diretrizes Nacionais para a

Educação Especial na Educação

Básica (2001).

A Constituição Federal (1988) assegura que a educação é um direito social e que devem ser proporcionados meios de acesso à educação. A Constituição diz também que compete à União, aos Estados e ao Distrito Federal legislar corretamente sobre a educação (BRASIL, 1988).

A Lei n. 9.394, de 20 de dezembro de 1996, mais conhecida como a Lei de Diretrizes e Bases da Educação Nacional, estabelece as diretrizes e bases da educação nacional. Essa Lei certifica é dever do Estado com educação escolar pública o

[...] atendimento educacional especializado gratuito aos educandos com deficiência, transtornos globais do desenvolvimento e altas habilidades ou superdotação, transversal a todos os níveis, etapas e modalidades, preferencialmente na rede regular de ensino (BRASIL, 1996, não paginado).

\section{As Diretrizes Nacio-} nais para a Educação Especial na Educação Básica declaram que os alunos atendidos em classe especial devem ser assegurados por:

a) Professores especializados em educação especial;

b) Organização de classes por necessidades educacionais especiais apresentadas, sem agrupar alunos com diferentes tipos de deficiências; c) Equipamentos $\mathrm{e}$ materiais específicos;

d) Adaptações de acesso ao currículo

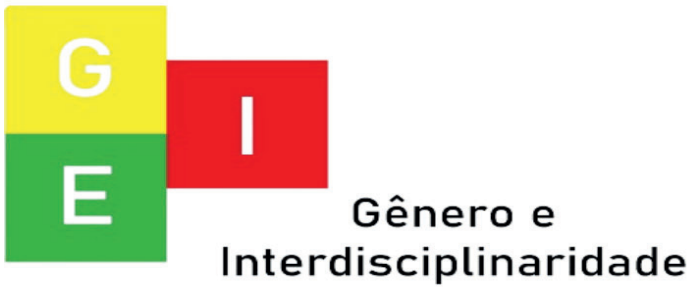


ISSN: 2675-7451

Vol. 02 - n 06 - ano 2021

Editora Acadêmica Periodicojs

e adaptações nos elementos curriculares;

e) Atividades da vida autônoma e social no turno inverso, quando necessário (BRASIL，2001, p. 52).

Essa lei ainda dá características de uma sala especial, que é uma sala em escola de ensino regular, onde existe uma estrutura adaptada e um professor de educação básico especial apto para utilizar métodos e técnicas didáticas, além de recursos pedagógicos específicos, conforme a necessidade pedagógica de cada aluno (BRASIL, 2001).

Para que haja uma educação de qualidade, é necessário que a prática educacional implantada no Brasil seja repensada, para que algumas situações sejam resolvidas e atenda a todas as pessoas de maneira eficaz e igualitária.
É importante também que o professor desenvolva um currículo com flexibilidade necessária às condições do aluno, além de, quando necessário, desenvolver atividades extras (BRASIL, 2001).

Os currículos escolares devem receber uma adaptação tendo em vista à diversidade da comunidade escolar partindo para a mudança onde possa atender as necessidades particulares dos alunos, considerando que a inclusão provoca mudanças no ambiente escolar apontando oportunidades iguais para todos os educandos, dando chances educacionais formais e sociais para alunos com TEA abrindo caminhos para uma escola inclusiva que respeite as características de cada estudante, que ofereça alternativas pedagógicas que atendam às necessidades educacionais de cada aluno: uma

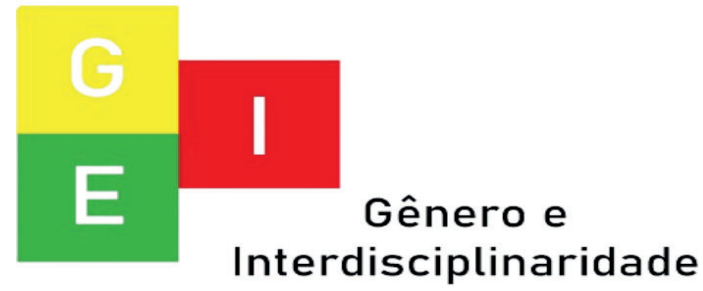


ISSN: 2675-7451

Vol. 02 - n 06 - ano 2021

Editora Acadêmica Periodicojs

escola que ofereça tudo isso num

ambiente inclusivo e acolhedor,

onde todos possam conviver e aprender com as diferenças.

A Declaração Universal dos Direitos Humanos (1948), no artigo 26 afirma que

1. Todo ser humano tem direito à instrução. A instrução será gratuita, pelo menos nos graus elementares e fundamentais. A instrução elementar será obrigatória. A instrução técnico-profissional será acessível a todos, bem como a instrução superior, esta baseada no mérito.

2. A instrução será orientada no sentido do pleno desenvolvimento da personalidade humana e do fortalecimento do respeito pelos direitos do ser humano e pelas liberdades fundamentais. A instrução promoverá a compreensão, a tolerância e a amizade entre todas as nações e grupos raciais ou religiosos e coadjuvará as atividades das Nações Unidas em prol da manutenção da paz.

3. Os pais têm prioridade de direito na escolha do gênero de instrução que será ministrada a seus filhos (FUNDO DAS NAÇÕES UNIDAS PARA A INFÂNCIA, 1948, não paginado).

Ou seja, a educação é um direito assegurado, porém, nem sempre esse direito é associado com qualidade de ensino, tendo em vista a desigualdade social que favorece a uns e desfavorece na mesma proporção outros. Desta forma, a educação inclusiva visa romper com esses paradigmas pré-estabelecidos e

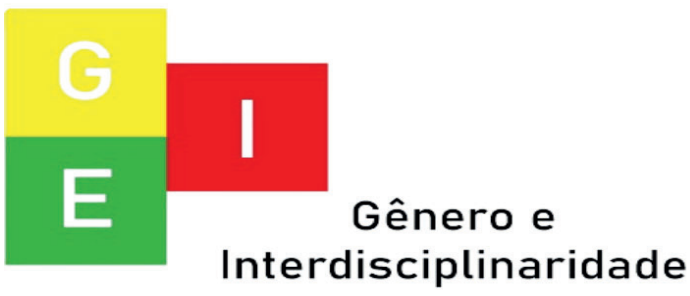


ISSN: 2675-7451

Vol. 02 - n 06 - ano 2021

Editora Acadêmica Periodicojs

abater esse índice de desigualdade, ofertando uma educação de qualidade a todos.

Para que sejam recebidos os alunos com TEA, o professor precisa estar apto para lidar com as diferenças individuais e criar metodologias diversificadas, garantindo assim o desenvolvimento de seus alunos, visando sempre à inclusão social.

A educação inclusiva envolve um processo de preparação do professor, considerando as diferenças e dificuldades individuais do aluno, por isso a importância da mudança de postura desses profissionais visando o desenvolvimento da aprendizagem dos alunos.

Os profissionais da educação necessitam estar dispostos a mudança e revendo constantemente os seus conceitos, valores e ideologias, para que seja pos- sível atuar como facilitador da conscientização na construção da cidadania, pois o processo de construção necessita partir da sua prática e de seus conhecimentos. Sobre a formação, Nóvoa (1995) afirma que:

Deve estimular uma perspectiva crítico reflexiva, para haver pensamento autônomo e que facilite as dinâmicas de autoformação participada. Estar em formação implica um investimento pessoal, um trabalho livre e criativo sobre os percursos e os projetos próprios, com vista à construção de uma identidade, que é também uma identidade profissional (NÓVOA, 1995, p. $25)$.

Incluir um aluno com TEA no ambiente escolar é bem mais do que inserí-lo numa escola

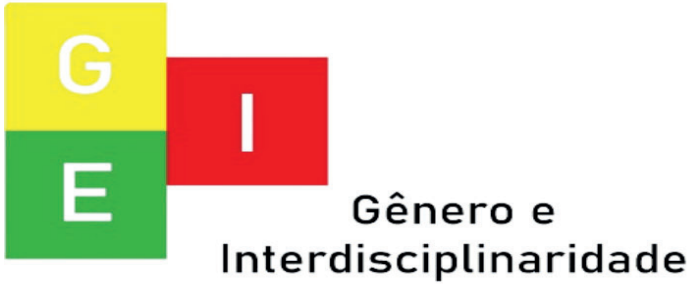


ISSN: 2675-7451

Vol. 02 - n 06 - ano 2021

Editora Acadêmica Periodicojs

regular, é necessário proporcionar aprendizagens significativas para as crianças, para que suas potencialidades sejam evidenciadas (PEREIRA et al., 2015)

\section{Tecnologias da educação para os alunos com TEA}

A tecnologia assistiva é uma ferramenta de acessibilidade e inclusão, com o intuito de agregar tecnologia e inclusão, em uma ferramenta capaz de ajudar alunos com necessidades especiais (TENÓRIO; VASCONCELOS, 2014).

Santos (2010, p. 54) define tecnologias assistivas como "[...] os recursos que visam a expansão de possibilidades dos portadores de necessidades especiais."

É importante que o professor aja como mediador entre o material e o aluno, fazendo com que exista um processo de aprendizagem e não de limitação.

As funções e definições dos recursos que se referem à tecnologia assistiva (TA), segundo Gonçalves (2010, p. 41) são:

[...] uso e implementação de qualquer instrumento, serviço, suporte, estratégia e prática que vão auxiliar na funcionalidade e melhorar os resultados esperados para a realização de uma atividade, seja ela acadêmica, atividade de vida diária, mobilidade, locomoção e comunicação. Portanto, pode ser classificado como sendo qualquer item, produto ou equipamento, adquirido e produzido comercialmente ou personalizado, com o intuito de manter, melhorar ou incrementar as habilidades funcionais de indivíduos com deficiência (GON-

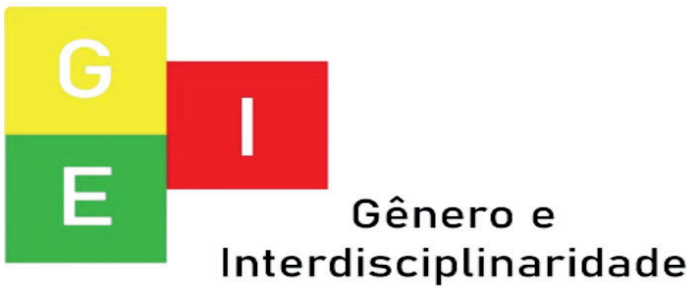


ISSN: 2675-7451

Vol. 02 - n 06 - ano 2021

Editora Acadêmica Periodicojs

ÇALVES, 2010, p. de aula, o uso desses aparelhos 41).

faz com que haja maior interação

entre o aluno e a prática educati-

São diversas as estratégias de intervenção no processo do desenvolvimento da criança com TEA, e o uso da tecnologia é uma delas. A respeito disso, Walter (2011, p. 3) afirma que

A inclusão de alunos com necessidades especiais na classe regular implica o desenvolvimento de ações adaptativas, visando à flexibilização do currículo, para que ele possa ser desenvolvido de maneira efetiva em sala de aula, e atender as necessidades individuais de todos os alunos (WALTER, 2011, p. 3).

Como uso de tecnologia assistivas, podemos citar o uso de Ipad ou Tablets. Juntamente com os conteúdos trabalhados em sala va, sendo primordial para o desenvolvimento das habilidades da escrita, leitura e comunicação (TENÓRIO; VASCONCELOS, 2014).

Dohme (2011, p. 103) afirma que o uso do Ipad é primordial para criar portas para a comunicação e mostra que

[...] a criança necessitará expressar aquilo que deseja, dentro do contexto que se encontra a história. Ela poderá ser solicitada a montar as próprias frases que expressarão alguma ideia solicitada, ou também, poderá escolher livremente que tipo de ideia ou situação que comunicar e identificar a forma de comunicação adequada para isso. Certamente, isto será um exercício cres-

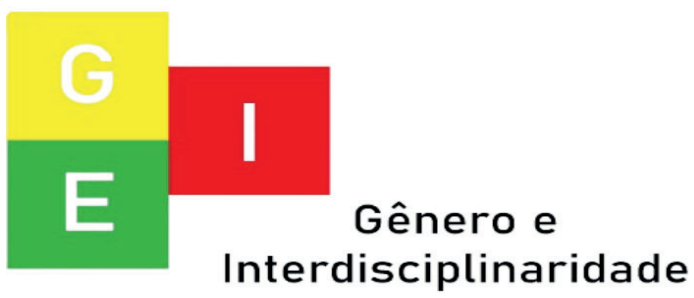


ISSN: 2675-7451

Vol. 02 - n 06 - ano 2021

Editora Acadêmica Periodicojs

cente de criatividade

e de expressividade, como também a identificação de novas formas de linguagem e de vocabulário (DOHME, 2011, p. 103).

Dessa forma, vemos que o aluno pode usar essas situações para montar e elaborar frases e criar sua própria comunicação. Além do uso da tecnologia para escrita, as tecnologias podem ser adotadas também para jogos, tanto musicais, quanto de soletração, história, pintura e encaixe.

Os jogos têm um objetivo e fator principal que “[...] é a facilitação do poder de concentração. Trabalhar com algo que se gosta, que desafia e que 'tende' a um bom resultado exige atenção. Esta virá como consequência do envolvimento" (DOHME, 2011, p. 110).
A tecnologia tem o po-

der de despertar na criança a motivação, além de ser uma atividade atrativa e desafiadora, pois faz com que ela veja possibilidades e use habilidades. Além desses jogos, podem ser usados também jogos de concentração, como raciocínio lógico e leitura.

Alguns aplicativos podem ser usados para o estímulo e orientação das crianças com TEA, esses jogos são importantes pois auxiliam na concentração, foco e raciocínio das crianças. Dentre os jogos podemos citar alguns:

ABC do autismo: auxilia no processo de alfabetização de crianças com o transtorno de desenvolvimento. $\mathrm{O}$ jogo possui 4 níveis para ganhar a atenção dos autistas: nos dois primeiros níveis a criança começa aprendendo habilidades como discriminação e transposição. Do

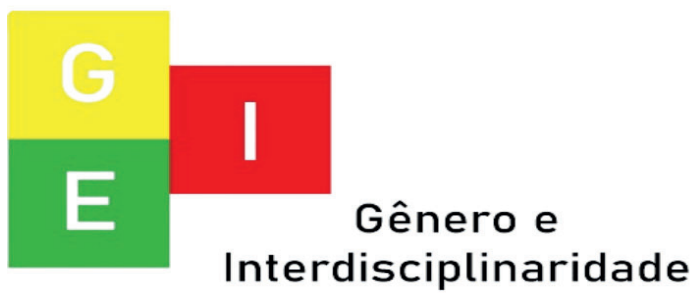


ISSN: 2675-7451

Vol. 02 - n 06 - ano 2021

Editora Acadêmica Periodicojs

terceiro ao quarto nível, o jogo fica mais complexo, onde entram questões sobre letramento, que engloba a repartição de sílabas, conhecimento de vogais e formação de palavras.

Puzzle 4 Kids: O jogo estimula as crianças a desenvolver enigmas e aprender as palavras que designam as coisas, aperfeiçoando assim a leitura. Auxilia as crianças a desenvolver habilidades motoras. Os aplausos e a torcida no jogo ajudam a criança a se sentir motivada para a continuação da construção do vocabulário, memória e habilidades de correspondência e cognição enquanto brinca.

ComFIM: tem como objetivo a promoção de habilidades de comunicação em pessoas autistas. Estimula a interação do autista com o personagem virtual, para depois incentivar a interação com outro jogador

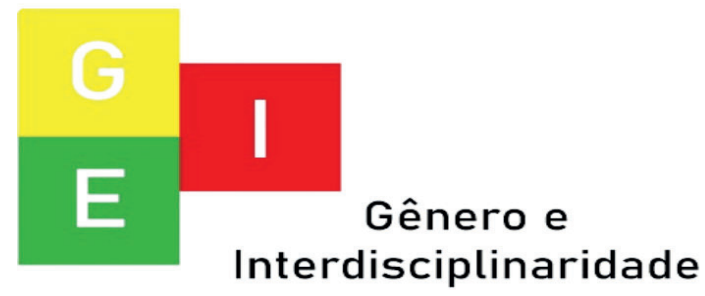

A Educação é um direito de todos os cidadãos e precisa ser orientada no sentido do pleno desenvolvimento e do fortalecimento da personalidade. O respeito aos direitos e liberdades humanas, primeiro passo para a construção da cidadania, deve ser incentivado.

A educação inclusiva consiste em educar todas as crianças num mesmo contexto escolar, isso pode ampliar a visão de mundo da criança, bem como desenvolver oportunidades de convivências a todas as crianças.

Os desafios da aprendizagem são grandes e a escola regular ainda precisa encontrar meios que incluam verdadeiramente esses alunos no ambiente escolar, pois o que se observa é que a escola tem "que aceitar" es- 
ISSN: 2675-7451

Vol. 02 - n 06 - ano 2021

Editora Acadêmica Periodicojs

ses alunos mesmo sem ter as

condições necessárias

e professores especializados, somente para cumprir as leis de inclusão. No entanto, é necessário investir em uma educação inclusiva que realmente faça o aluno fazer parte do contexto escolar, pois somente assim será possível cumprir o direto de educação de qualidade pata todos.

Um ponto importante a ser salientado é a formação dos professores para que sejam capacitados as novas práticas da educação, de modo a atender as necessidades do ensino inclusivo. A educação continuada tem papel primordial na prática profissional.

A adaptação do currículo escolar não deve ser uma forma de deixar a criança acomodada, pelo contrário, deve impor desafios para a aprendizagem, fazendo com que haja o interesse

e força de vontade de vencer os obstáculos vividos.

Acreditamos que o uso de tecnologias possibilita a eficácia no que diz respeito ao desenvolvimento de crianças com autismo inseridas no ambiente escolar, de forma que facilita o processo de ensino-aprendizagem dos alunos, o que pode gerar benefícios e resultados significativos tanto para o aluno, quanto para o professor.

\section{REFERÊNCIAS}

ALVES, Cândida Helena Lopes.

Diagnóstico do autismo. In: MATOS, Daniel Carvalho (Org.). Análise do comportamento aplicada ao desenvolvimento atípico com ênfase em autismo. São Luís, Editora AISCA, 2016.

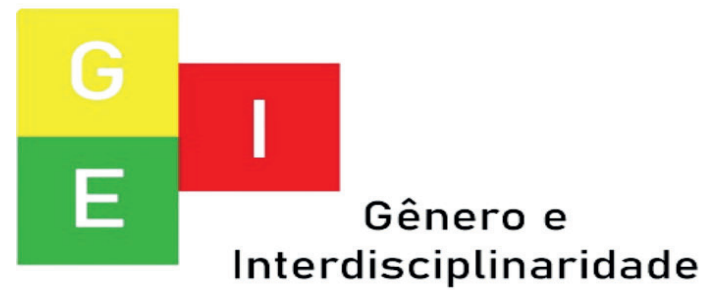


ISSN: $2675-7451$

Vol. 02 - n 06 - ano 2021

Editora Acadêmica Periodicojs

TEA: Transtorno do Espectro

BRASIL. Constituição Federal. Autista. Disponível em: <https://

1988. Disponível em: <http:// drauziovarella.uol.com.br/doen-

WWw.planalto.gov.br/ccivil_03/ cas-e-sintomas/tea-transtorno-

constituicao/constituicao.htm>. - do-espectro- autista-ii/>. Acesso

Acesso em: 05 dez. $2017 . \quad$ em: 04 abr. 2018.

BRASIL. Lei n. 9.394, de 20 de DOHME, Vania. Atividades lúdezembro de 1996. Estabelece as dicas na educação: o caminho de diretrizes e bases da educação tijolos amarelos do aprendizado. nacional. Disponível em: <http:// 6.ed. Petrópolis, RJ: Vozes, 2011. www.planalto.gov.br/ccivil_03/ leis/L9394.htm>. Acesso em: 05 dez. 2017.

FUNDO DAS NAÇÕES UNIDAS PARA A INFÂNCIA (UNICEF). Declaração Universal Dos BRASIL. Ministério da Educação. Diretrizes e nacionais para a educação especial na educação básica. São Paulo: SecretaDireitos Humanos. 1948. Disponível em: <https://www.unicef. org/brazil/pt/resources_10133. htm>. Acesso em: 05 dez. 2017. ria de Educação Especial; MEC; SEESP, 2001. Disponível em: NÓVOA, Antonio. Formação de $<$ http://portal.mec.gov.br/seesp/ Professores e Profissão Docente. arquivos/pdf/diretrizes.pdf $>$. Acesso em: 05 dez. 2017. In: NÓVOA, Antonio (org.) Os Professores e a sua formação. Lisboa: Publicações Dom QuixoBRUNA, Maria Helena Varella. te, 1995.

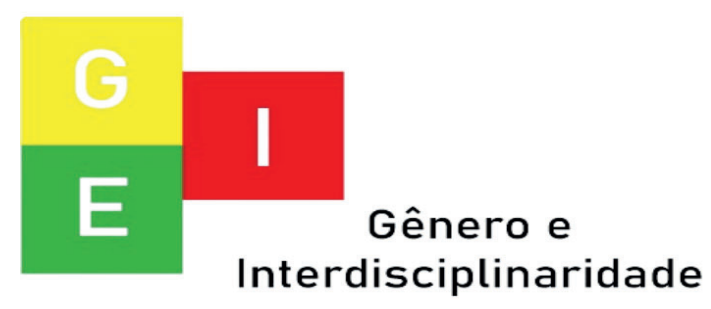


ISSN: 2675-7451

Vol. 02 - n 06 - ano 2021

Editora Acadêmica Periodicojs

em: 9 abr. 2018.

PORTAL EDUCAÇÃO. A im-

portância da educação inclusi-

SANTOS, Sostenes Vieira. Eduva na educação infantil. 2018.

Disponível em: $<$ https://www.

portaleducacao.com.br/conteudo/

artigos/idiomas/a-importancia-

-da- educacao-inclusiva-na-edu-

cacao-infantil/55604>. Acesso

em: 10 mar. 2018.

cação Inclusiva: considerações

acerca do uso das tecnologias

contemporâneas. Revista Espa-

ço Acadêmico, n. 109, jun. 2010,

p.51-57. Disponível em: <http://

WWw.periodicos.uem.br/ojs/in-

dex.php/EspacoAcademico/arti-

cle/viewFile/8902/5 693>. Acesso

RODRIGUES, M.de O. Transtorem: 11 abr. 2018.

nos Globais do Desenvolvimento

(TGD). Presidente Prudente: Se-

cretaria Municipal de Educação

TENÓRIO, Mylena Carla Alde Presidente Prudente/SP, 2012. meida; VASCONCELOS, Norma Abreu e Lima. Autismo: a SANTOS, Fabiana Haro dos; tecnologia como ferramenta GRILLO, Mariana Aparecida. assistiva ao processo de enTranstorno do Espectro Autista - sino e aprendizagem de uma TEA. Colloquium Humanarum, criança dentro do espectro. DisPresidente Prudente, v. 12, n. 3, ponível em: <http://editorarep.30-38, jul/set2015. Disponí- alize.com.br/revistas/cintedi/ vel em: <http://revistas.uno- trabalhos/Modalidade_1daeste.br/revistas/ojs/index.php/ch/ tahora_07_10_2014_16_44_33_ article/view/1417/1544>. Acesso idinscrito_387_654 e cb-

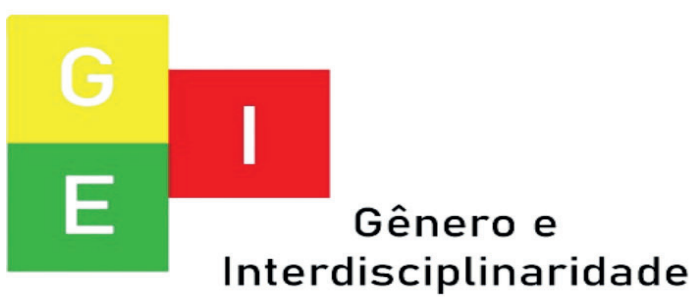


ISSN: 2675-7451

Vol. 02 - n 06 - ano 2021

Editora Acadêmica Periodicojs

$08429600021 \mathrm{f} 5 \mathrm{e} 35 \mathrm{~b} 9 \mathrm{dc} 5266 \mathrm{~d} 9$.

pdf $>$

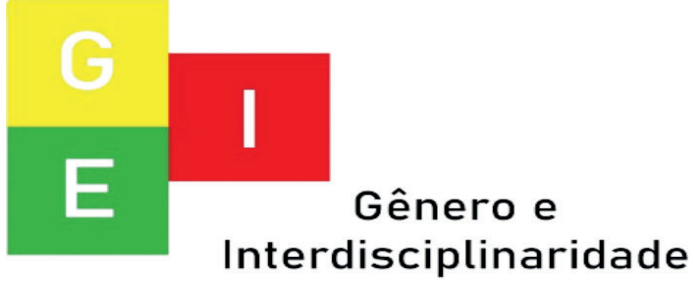

